Hamas el espejismo sirio

Ángel Horacio Molina

páginas / año 8 - n 18 Septiembre - Diciembre / ISSN 1851-992X

/pp. 67-77 / 2016

http://revistapaginas.unr.edu.ar/index.php/RevPaginas

\title{
Hamas en el espejismo sirio
}

\author{
Hamas in the Syrian mirage
}

\author{
Ángel Horacio Molina \\ Universidad Al Mustafa, Irán \\ angelhmolina@gmail.com
}

\section{Resumen}

El presente trabajo tiene como finalidad repasar las posiciones adoptadas por el Movimiento de Resistencia Islámico con relación al conflicto sirio y las consecuencias de las mismas en un escenario regional caracterizado por la lucha de algunos Estados en pos de la consolidación de espacios hegemónicos.

\section{Palabras clave}

Hamas; Siria; Palestina; Conflicto árabe - israelí; Primaveras Árabes

\section{Abstract}

This paper aims to review the positions adopted by the Islamic Resistance Movement regarding the Syrian conflict and the consequences thereof in a regional scenario characterized by the struggle of some states towards the consolidation of hegemonic spaces.

\section{Keywords}

Hamas; Syria; Palestine; Arab - Israeli conflict; Arab Springs 


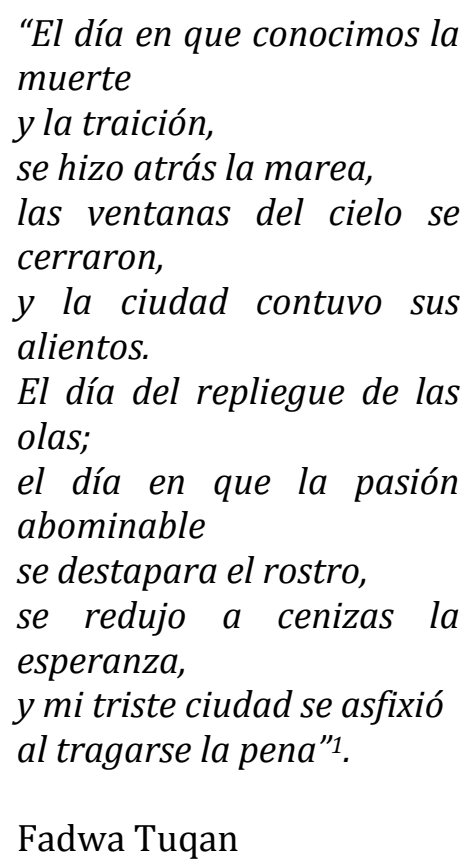

\section{Introducción}

El conflicto en Siria dista mucho de ser simplemente un enfrentamiento de orden interno, de su resolución depende tanto la posibilidad de algunos actores de convertirse en potencias regionales y consolidar sus áreas de influencia ${ }^{2}$ como el futuro político de varios personajes no sirios que utilizan a los grupos en el terreno para fortalecer sus aspiraciones personales en sus respectivos países ${ }^{3}$.

En Siria, por otra parte, se materializa una nueva forma de intervención que supone la descomposición de cualquier orden estatal, generando espacios de inestabilidad que posibilitan la reconfiguración de las fronteras garantizando, al mismo tiempo, la extracción de los recursos del país. "Es el mundo en general el que está en guerra civil en Siria", sostiene el chileno Rodrigo Karmy Bolton haciendo hincapié tanto en el carácter trasnacional del conflicto como en la racionalidad

1Fadwa Tuqan. "Mi ciudad está triste". Disponible en: http://descontexto.blogspot.mx/2012/11/cinco-poemas-de-fadwa-tuqan.html

${ }^{2}$ Nos referimos fundamentalmente a Arabia Saudita, Irán, Turquía e Israel.

3 Tal es el caso del presidente Turco, Tayyip Erdogan, y del Ministro de Defensa saudí, Muhammad Ibn Salman.

${ }^{4}$ Rodrigo Karmy Bolton, “¿Qué es el terrorismo?, o cómo el imperialismo contemporáneo produce guerras civiles”. El desconcierto (Chile), 19 de septiembre de 2016). Disponible en http://www.eldesconcierto.cl/debates-y-combates/2016/09/19/que-es-el-terrorismo-o-como-elimperialismo-contemporaneo-produce-guerras-civiles/ 


\section{Ángel Horacio Molina}

económica que encierra este nuevo tipo de “(...) dispositivo geoeconómico de carácter global, orientado a la gestión de las poblaciones".

Las fuerzas palestinas de resistencia tomaron posiciones diversas en el conflicto abierto en el corazón del país árabe, desde el claro respaldo del Frente Popular para la Liberación de Palestina- Comando General (FPLP-CG) al gobierno sirio hasta el apoyo del Movimiento de Resistencia islámica (Hamas) a los "rebeldes", pasando por la cautela de la Autoridad Nacional Palestina y la tibia condena del Frente Popular para la Liberación de Palestina (FPLP) a la intromisión extranjera.

En las líneas que siguen daremos cuenta de la postura asumida por Hamas en el espacio sirio y las respectivas consecuencias de la misma, procurando entender dicho posicionamiento en el marco de un proceso regional donde las fuerzas vinculadas ideológicamente con la Hermandad Musulmana parecían estar en condiciones de capitalizar de mejor manera los escenarios derivados de las llamadas "primaveras árabes".

\section{Hamas en el "Eje de la Resistencia"}

Con la expulsión de los referentes de Hamas de Jordania, luego de la ilegalización del Movimiento, en 1999 y el posterior traslado de las "oficinas políticas" de la organización a Damasco, Siria conseguía referenciarse como el "protector" de un amplio espectro de grupos palestinos contrarios a la Autoridad Nacional Palestina, que ideológicamente iban desde el marxismo del FPLP hasta el Islam militante de Hamas. Como respuesta a la ampliamente difundida idea del "Eje del Mal" utilizada por la administración Bush para referirse a sus enemigos en Oriente Medio, algunos medios de comunicación de la región ${ }^{5}$, primero, y funcionarios de Irán y Siria, luego, comenzaron a utilizar la noción de "Eje de la Resistencia" para dar cuenta de las acciones de Irán, Siria, Hizbullah y Hamas en el escenario regional.

El establecimiento de Musa Muhammad Abu Marzooky Khaled Meshal, máximos referentes de Hamas en el exilio, en 2001 en la capital siria, dio cuenta de las estrechas relaciones que el gobierno de Damasco estaba dispuesto a mantener con el movimiento, a pesar de las coordenadas ideológicas del mismo, que lo emparentaban con la Hermandad Musulmana siria, y las buenas relaciones que este mantenía con algunos países árabes abiertamente hostiles a las posiciones sirias, como las monarquías del Golfo Pérsico.

El triunfo de Hamas en las elecciones palestinas de 2006 fue recibido con euforia por Siria e Irán, y confirmó a los ojos de Bashar Al Asad y sus partidarios la necesidad de garantizar el apoyo al movimiento, asumiendo los costos que pudieran derivarse del mismo. Así, en febrero de 2007, en la reunión del Comité Central del

\footnotetext{
5 Por ejemplo los periódicos Az-Zahful-Akhdar(Libia) y Jomhuri-ye Eslami (Irán).
} 
Partido Baath previa a las elecciones presidenciales de ese año, Al Asad manifestó la necesidad de continuar ayudando a Hamas y Hizbullah a pesar de las sanciones que, desde 2004, Estados Unidos había impuesto a Damasco como resultado de este apoyo. "El presidente fue claro en que Siria continuará apoyando a estos dos movimientos", comentaba el batista Mostafá al Meqdad al finalizar la reunión6.

El grado de protección que Damasco ofreció a la dirigencia de Hamas fue tal que, cuando en 2006 la organización capturó a un soldado israelí, Khaled Mashal anunció el éxito del operativo ante un grupo de periodistas especialmente convocados por el gobierno sirio en un hotel damasceno ${ }^{7}$.La estrategia de Al Asad no solamente apuntaba a aumentar la influencia de Siria en el escenario regional, particularmente en el arco palestino contrario a los acuerdos con Israel, sino también a debilitar el discurso de organizaciones opositoras sirias como la Hermandad Musulmana que, aunque proscripta, continuaba apelando desde grupos y personajes afines, a la caracterización sectaria del gobierno llamando al levantamiento contra el "poder alawita". Como veremos más adelante, el discurso sectario había cobrado nuevas fuerzas en la región a partir de 2003 y Bashar Al Asad fue consciente que la continuidad de su gobierno pasaba por la desarticulación del mismo.

La alianza con Siria significaba también el fortalecimiento de los lazos que unían a Hamas con el apoyo financiero y militar de Irán, país que desde 1990 había establecido excelentes relaciones con la dirigencia de Hamas. Fue través del país árabe como habría llegado el apoyo financiero iraní a la organización palestina ${ }^{8}$. Mahmud Abbas señalaba con molestia en 2010 que Hamas recibía quinientos millones de dólares anuales de parte de Irán; “Hamas es financiado por Irán” repetía por entonces el dudosamente legítimo Presidente de la Autoridad Nacional Palestina. ${ }^{9}$

\section{Las “primaveras árabes” y la Hermandad Musulmana}

Cuando a principios de 2011 una ola de revueltas sacudió al Mundo Árabe y se abrieron algunos canales institucionales de participación política, un conjunto de organizaciones vinculadas ideológicamente con la Hermandad Musulmana se encontró de repente con escenarios que les permitía capitalizar el descontento contra los gobiernos que los habían proscripto, aprovechando además su contacto

\footnotetext{
${ }^{6}$ http://www.haaretz.com/news/syrian-president-vows-to-keep-supporting-hezbollah-hamas$\underline{1.212293}$

7 Barry Rubin, The truth about Syria, New York, Palgrave Macmillan, 2007,p. 78.

${ }^{8} \mathrm{http://www.irantracker.org/military-activities/iran-hamas-relationship-2008}$

${ }^{9}$ http://www.worldtribune.com/worldtribune/WTARC/2010/me hamas0005 01_05.asp
} 


\section{Ángel Horacio Molina}

con las bases a partir de las redes de asistencia social construidas a lo largo de años de trabajo.

La llegada al poder en Túnez del Islam militante de la mano de An Nahda en 2011 y el triunfo del ijwaní10 Muhammad Mursi en las elecciones presidenciales egipcias en 2012 (que materializó la máxima aspiración de la Hermandad a pesar del discutible papel de la misma en la revuelta que condujo a la caída de Hosni Mubarak ${ }^{11}$ ), hacían prever un rol protagónico para la organización en los procesos políticos post "primaveras árabes".

Para Hamas y su gobierno en la Franja de Gaza, la caída de Mubarak no podía ser más oportuna en momentos en el que el dictador egipcio había iniciado, en sintonía con las acciones israelíes para aumentar el aislamiento gazatí, la construcción de un muro subterráneo del lado egipcio de la frontera que garantizaría el fin de los túneles que permiten el abastecimiento de la población palestina de Gaza ${ }^{12}$.

El gobierno de Mursi rápidamente manifestó su solidaridad para con Hamas invitando a la capital egipcia, en julio de 2012, al Primer Ministro del gobierno gazatí, Ismail Haniyeh, y al líder de Hamas Khaled Mashal, lo que generó gran malestar en la Autoridad Nacional Palestina ${ }^{13}$. Ambos referentes del movimiento islámico mantuvieron además sendas reuniones con la dirigencia de la Hermandad Musulmana egipcia para discutir la situación de la región, en general, y la de Gaza, en particular.

Hamas reconoce en la Hermandad Musulmana egipcia la matriz ideológica y organizacional de la cual proviene; como señala Khaled Hroub:

"Hamas es el resultado de la metamorfosis interna de las Hermandades Musulmanas Palestinas que tuvo lugar a finales de 1980. Oficialmente, la rama palestina de la Hermandad Musulmana se fundó en 1946 en Jerusalén (...). Los fines, estructura y perspectivas de la Hermandad Musulmana Palestina provienen de las líneas principales de pensamiento de la organización madre en Egipto".14

Para cuando Mursi asumió la presidencia, los acontecimientos en Siria se habían precipitado, dando lugar a un conflicto que involucró a distintos actores locales y foráneos. No nos detendremos en las líneas explicativas que intentan dar cuenta del origen de la situación siria, simplemente señalaremos que la actitud de

\footnotetext{
${ }^{10}$ Ijwaní: miembro de la Hermandad Musulmana (Al-Ijwán ul-Muslimún)

${ }^{11}$ Wilda Western, Alejandra Galindo e Indira Bernal, Voces, tramas y trayectorias: las protestas populares en Medio oriente y norte de África. México, Universidad Autónoma de Nuevo León Universidad de Monterrey, 2014.

${ }^{12}$ http://www.abc.es/20091210/internacional-asia/egipto-construye-muro-subterraneo20091210.html

${ }^{13}$ http://www.jpost.com/Middle-East/Hamas-invites-Egypts-Mursi-to-visit-Gaza

${ }^{14}$ Khaled Hroub, Hamas, una guía introductoria. México, Editorial Popular, 2006, p. 39.
} 
Hamas con respecto a las fuerzas antagónicas sirias fue acompañar la postura de los países que surgían, en esa coyuntura, como sus más firmes defensores y no parecían atravesar una situación crítica como la del gobierno sirio; nos referimos a Turquía bajo el gobierno de Erdogan y Egipto durante la presidencia de Mursi.

\section{Mursi y la exacerbación del discurso sectario}

Si Erdogan fue el anfitrión de las fuerzas políticas opositoras sirias en el exilio desde mediados de 2011, Mursi lo fue de las fuerzas más retrógradas del Islam militante sunni en junio 2013.Con la presencia de más de quinientos representantes de cerca de 70 organizaciones de distintas corrientes salafis ${ }^{15}$ y encabezada por el mediático Youssef al-Qaradawi, la reunión organizada por la Hermandad Musulmana egipcia llamó explícitamente a la jihad en Siria, atacando al gobierno de ese país y definiéndolo como un "gobierno sectario"16.

Desde 1979 Arabia Saudita había recurrido sistemáticamente al discurso sectario para "encapsular" la revolución islámica dentro del mundo shií, pero a partir de la caída de Saddam Hussein en 2003, fueron las monarquías árabes, con el rey jordano Abdullah II a la cabeza, las que retomaron esta línea discursiva para llamar la atención sobre los peligros que supondría para sus intereses la llamada "Media Luna Shií" (Irán, Irak, Siria y El Líbano).

Con el apoyo de Turquía y Qatar, el Egipto de Mursi se ubicó tempranamente entre los enemigos del gobierno sirio y permitió que el discurso sectario se expandiera en la población egipcia acompañando en clave religiosa su postura con relación al conflicto en Siria. La muestra más terrible de la permisibilidad gubernamental con respecto a la intolerancia para con las minorías islámicas fue el caso del asesinato del dirigente egipcio shií Sheij Hassan Shihata. Apenas uno días después de la reunión auspiciada por el gobierno egipcio y la Hermandad Musulmana, una turba se dirigió a la casa del dirigente shií asesinándolo junto a cuatro de sus seguidores sin que el gobierno tomara medidas para dar con sus

\footnotetext{
15 Salafismo: corriente dentro del Islam sunni que clama por el regreso al modo de vida de los "piadosos antepasados" (salaf) y que atribuye la decadencia del Mundo Islámico al abandono del Corán y la Sunna (comportamiento del Profeta y las primeras generaciones de musulmanes). El salafismo actual, producto del esfuerzo de las monarquías árabes por combatir al "socialismo árabe", se caracteriza por un rigorismo que empobrece y reduce a la literalidad el mensaje coránico, haciendo de esta corriente una de las manifestaciones más toscas del Islam contemporáneo. Ver: Felipe Maillo Salgado. Diccionario de Historia Árabe e Islámica. Madrid, Abada Editores, 2013.

${ }^{16}$ http://www.joshualandis.com/blog/clerics-in-egypt-call-for-global-jihad-against-regimes-shiiteallies /

http://www.reuters.com/article/us-syria-crisis-sunnis-jihad-idUSBRE95C16U20130613
} 


\section{Ángel Horacio Molina}

asesinos, a pesar de que el crimen fue registrado y reproducido por las redes sociales ${ }^{17}$.

Restando valor a las explicaciones políticas y geoestratégicas, los conflictos en la región, incluyendo el sirio, fueron reducidos a enfrentamientos de tipo sectario, reproduciendo las mismas consignas que la Hermandad Musulmana enarbolara a principios de la década de los ochenta para llamar a la lucha armada contra el gobierno de Hafez $\mathrm{Al} \mathrm{Asad}{ }^{18}$. Maamun Homsi, por ejemplo, un destacado miembro de la oposición en el exilio y cercano a la dirigencia de Hamas, llamó en 2012 a exterminar a los miembros de la minoría alawi, calificándolos de "despreciables", sin que el Consejo Nacional Sirio o el movimiento palestino condenasen estas expresiones ${ }^{19}$. La gradual consolidación de los grupos salafíes en el escenario sirio en los años siguientes refleja el impacto de estas ideas en la construcción discursiva del "enemigo".

\section{Siria: lecturas equivocadas}

A partir de las previsiones y posicionamientos de sus aliados regionales (Turquía, Egipto y Qatar), la dirigencia de Hamas creyó inminente la caída del gobierno de Bashar Al Asad tras los levantamientos de 2011. Depuesto Mubarak en Egipto y con la Hermandad en ascenso buscando la presidencia del país, en febrero de 2012 Ismail Haniyeh, acompañado por Salah Sultan, un referente de la Hermandad Musulmana egipcia, y el propio Maamun Homsi, saludó "al heroico pueblo sirio que está buscando libertad y democracia"20.

La ruptura se materializó finalmente ese mismo año con la salida de Khaled Mashal y de Musa Muhammad Abu Marzook de Siria, el primero con destino a Qatar y el segundo a Egipto. El periodista gazatí Yusuf Al Maqid sostiene que "(...) las relaciones con EL régimen de Bashar Al Asad se cortaron después de la Revolución siria, estos eventos empujaron a Hamas a abandonar el Eje de la Resistencia y a unirse a un nuevo eje, formado alrededor del núcleo compuesto por Egipto, Qatar y Turquía"21.

Numerosas fuentes han señalado, incluso, la presencia de milicianos de Hamas combatiendo junto a los "rebeldes sirios"22. En junio de 2013, el periódico libanés Al Ajbar, cercano a Hizbullah, denunció la presencia de miembros de la organización palestina combatiendo Al gobierno sirio en las decisivas batallas de

\footnotetext{
${ }^{17} \underline{\mathrm{http}}: / /$ www.youtube.com/watch?v=oivHySUoRjM\&bpctr $=1478106440$

18 Es interesante señalar que desde 2011, la Hermandad Musulmana siria ha intentado distanciarse del discurso sectario que caracterizó sus posicionamientos anteriores.

${ }^{19}$ http://www.aljazeera.com/indepth/features/2012/03/201237101424192726.html

${ }^{20} \mathrm{http}: / /$ www.ibtimes.co.uk/hamas-leader-salutes-heroic-syrians-cairo-s-304201

${ }^{21}$ https://warisboring.com/hamas-is-running-out-of-allies-2ec6f2a35a78\#.yxdnnrlci

${ }^{22}$ http://sana.sy/es/?p=30945
} 
Qusayr ${ }^{23}$. Ibrahim Khader, periodista palestino que se encuentra cubriendo el conflicto sirio, ha manifestado que ex miembros de las Brigadas Ezzedine al-Qassam (brazo armado de Hamas) se encuentran brindando apoyo a los rebeldes, instruyéndolos fundamentalmente en la construcción de túneles. ${ }^{24}$

Contra todo pronóstico, y cuando se esperaba incluso un ataque inminente de los aviones estadounidenses, en 2013 el escenario sirio comenzó a cambiar radicalmente, con la participación de fuerzas de Hizbullah y de las unidades de élite de Irán, primero, y el involucramiento directo de Rusia, después. Sin embargo, el golpe más duro contra Hamas llegó el 3 de julio de ese mismo año, cuando el Abdul Fatah Al Sisi encabezó la asonada militar que quitó a Muhammad Mursi del poder en Egipto.

Las lecturas erróneas congelaron los efectivos apoyos de Siria e Irán al movimiento islámico, al tiempo que se hizo evidente la fragilidad de las alianzas establecidas con quienes se esperaba fuesen los nuevos patrocinadores. El "arco sunni" fue incapaz de garantizar los recursos y el apoyo político que anhelaban desde la dirección de la organización. Incluso se había especulado con recibir algún tipo de "compensación" saudí 25 ante este realineamiento que afectaba los intereses de Irán, el principal enemigo regional de la monarquía árabe. En este sentido, Ibrahim al-Madhoun, analista político del periódico Al Risalah (cercano al Movimiento de Resistencia Islámico) manifestó que "(...) Hamas esperaba construir sólidas relaciones con Arabia Saudí, en especial luego de la llegada al poder del Rey Salman. Pero esos planes se vieron frustrados por complicaciones políticas surgidas dentro del reino". ${ }^{26}$

El ala militar del Hamas fue la primera en manifestar su malestar ante las decisiones que pusieron a todo el aparato político -militar en un alto grado de vulnerabilidad. Estas diferencias al interior de Hamas, agudizaron las ya existentes entre la dirigencia en el exilio y las bases combatientes ${ }^{27}$.

El devastador ataque israelí sobre la Franja de Gaza, desencadenado el 8 de julio de 2014, puso de manifiesto en grado de aislamiento en el que Hamas se encontraba. A pesar de la crudeza con la que fueron registradas y difundidas las imágenes de la agresión israelí sobre la población civil, los estados "amigos" de la

\footnotetext{
${ }^{23}$ http://www.middleeasteye.net/news/how-did-hamass-military-expertise-end-syrias-rebels$\underline{1129524334}$

${ }^{24}$ http://www.middleeasteye.net/news/how-did-hamass-military-expertise-end-syrias-rebels$\underline{1129524334}$

${ }^{25}$ Aun cuando la monarquía se había manifestado abiertamente contra la Hermandad Musulmana y apoyó explícitamente al gobierno golpista de $\mathrm{Al} \mathrm{Sisi} \mathrm{en} \mathrm{Egipto.}$

${ }^{26}$ http://www.al-monitor.com/pulse/originals/2016/06/gaza-hamas-resume-relations-iran.html

${ }^{27} \mathrm{http}: / /$ www.al-monitor.com/pulse/originals/2016/06/gaza-hamas-resume-relations-iran.html
} 


\section{Ángel Horacio Molina}

organización poco hicieron para detener la ofensiva de las fuerzas invasoras. Turquía, incluso, avanzó hacia la gradual normalización de relaciones con Israel mientras Gaza era agredida de tal manera que, según diversas ONGs en el terreno ${ }^{28}$, su reconstrucción podría llevar al menos veinte años.

\section{Reconstruyendo relaciones estratégicas}

La agresión israelí y la complacencia árabe ante la misma, obligó a la dirección de Hamas a revisar las posiciones asumidas al inicio de las "primaveras árabes".

Según un interlocutor del movimiento entrevistado por el periodista palestino Hazem Balousha, Hamas entiende que “(...) el mundo árabe está experimentando un rediseño de su mapa político. El régimen sirio está obteniendo avances en el terreno contra sus oponentes, Arabia Saudita está preocupada por su guerra en Yemen y Turquía está restaurando las relaciones con Israel. Como resultado, Hamas teme una continuación de su aislamiento debido a los acontecimientos regionales" 29 .

La primera medida tomada por la dirección de Hamas fue restablecer plenamente las relaciones con Irán, afectadas no sólo por el posicionamiento del movimiento con respecto a Siria sino también por su postura en relación al escenario yemení donde había manifestado su apoyo explícito a las fuerzas del depuesto Mansur Al Hadi (apoyado por Arabia Saudí) frente a las fuerzas de Ansarullah (respaldadas políticamente por Irán).

En febrero de 2016, con motivo de las celebraciones por el trigésimo séptimo aniversario del triunfo de la Revolución Islámica en Irán, Mohammed Nasr y Osama Hamdan encabezaron la delegación de Hamas que llegó a Teherán con el objetivo de reanudar completamente los vínculos con Irán. Las reuniones celebradas en la capital iraní incluyeron un encuentro con el popular General Qasem Suleimani, comandante de la Fuerza Quds, unidad militar iraní de élite de vital importancia en los conflictos de Siria e Irak.

Para enfatizar la buena predisposición de Hamas con respecto a Irán, por primera vez desde la ruptura con Damasco, el histórico dirigente de Hamas, Abu Marzook se refirió al país persa, enfatizando que su apoyo “(...) a la resistencia palestina, ya sea en logística, capacitación o fondos, es incomparable y está más allá de las capacidades de otros países."30

Incluso algunos referentes de la organización, como su representante en El Líbano, Raafat Murra, han manifestado la necesidad de restablecer también los lazos con el gobierno sirio, señalando la confluencia de objetivos entre Hamas y Hizbullah

\footnotetext{
${ }^{28}$ http://www.jornada.unam.mx/2014/08/31/mundo/021n1mun

${ }^{29} \mathrm{http}$ ://www.al-monitor.com/pulse/originals/2016/06/gaza-hamas-resume-relations-iran.html ${ }^{30} \mathrm{http}$ ://www.al-monitor.com/pulse/originals/2016/06/gaza-hamas-resume-relations-iran.html
} 
en su lucha contra Israel. "Somos conscientes de la importancia de Siria, su posición, su ubicación geográfica y los vínculos históricos entre Palestina y Siria ", declaraba Murra al periódico Daily Star en Beirut ${ }^{31}$.

Estos forzados realineamientos de Hamas tuvieron, lógicamente, repercusiones hacia el interior de la dirigencia del movimiento. En declaraciones recientes, los miembros de Hamas próximos a Khaled Meshal manifestaron que éste había decidido no presentarse a las próximas elecciones para la dirección del Comité Político del movimiento. "Asistimos a los últimos días del liderazgo de Khaled Meshal en Comité Político de Hamas. La influencia de Meshal en el movimiento ha decrecido a partir de su apuesta al "caballo incorrecto" cuando se movió de Damasco a Qatar"32, afirma el analista Shlomi Eldar.

\section{Ideas finales}

Las perspectivas erróneas con respecto al futuro del gobierno sirio y la intención de garantizar una relación favorable con el "gobierno post - Al Asad", llevaron a la dirección del Movimiento de Resistencia Islámico a cortar las relaciones con, hasta entonces, uno de sus aliados más importantes del Mundo Árabe. La esperanza de "compensaciones" de parte de los estados árabes por el realineamiento de Hamas y el quiebre del "Eje de la Resistencia", favoreció la adopción de esta medida que, al mismo tiempo, congelaba los vínculos con la República Islámica de Irán, fundamentales en cuanto a los recursos financieros y militares de la organización.

El golpe contra Mursi en Egipto y los apoyos determinantes conseguidos por el gobierno sirio en sus campañas militares, pusieron a Hamas en una situación de extrema vulnerabilidad en un escenario en el que sus "aliados" no estaban dispuestos a poner en peligro sus propios proyectos regionales para salir en defensa del movimiento palestino.

El regreso de Hamas a "Eje de la Resistencia" supone, en primer lugar, el reconocimiento por parte de su dirigencia del poco prudente cambio de alianzas realizado al estallar las "primaveras árabes" $\mathrm{y}$, en segundo término, el fortalecimiento del rol de Irán en el futuro de Hamas cuando los apoyos del Mundo Árabe parecen diluirse gradualmente.

En un escenario regional caracterizado por las disputas entre distintos Estados por ampliar y consolidar espacios hegemónicos, las recientes amenazas del

\footnotetext{
${ }^{31}$ http://www.jpost.com/Middle-East/Hamas-seeks-to-restore-ties-with-Syria-denies-pastsupport-for-rebels-395367

${ }^{32}$ http://www.al-monitor.com/pulse/originals/2016/06/khaled-meshaal-hamas-political-bureauismail-haniyeh-shura.html
} 


\section{Ángel Horacio Molina}

Ministro de Defensa israelí con respecto a un inminente y definitivo ataque a la Franja de Gaza ${ }^{33}$, puede leerse también como una respuesta a este rol protagónico que podría asumir Irán con relación a la supervivencia del Movimiento Islámico y la resistencia palestina.

\section{Bibliografía}

Barry Rubin. The truth about Syria. New York, Palgrave Macmillan, 2007.

Felipe Maillo Salgado. Diccionario de Historia Árabe e Islámica. Madrid, Abada Editores, 2013.

Ignacio Álvarez- Ossorio. Siria contemporánea. Madrid, Editorial Síntesis, 2009.

Khaled Hroub. Hamás, una guía introductoria. México, Editorial Popular, 2006.

Luis Mesa Delmonte (Coord.). Las relaciones exteriores de Siria. México, El Colegio de México, 2013.

Marta Tawil Kuri. Siria, Poder regional, legitimidad y política exterior. México, El Colegio de México, 2016.

Matthew Levitt. Hamás. España, Verticales de Bolsillo, 2008.

Michael Dumper (Ed.). Arab - IsraeliConflict (Vol. I, II, III y IV). New York, Routledge, 2009.

Mohamed Cherif Ferjani. Política y religión en el campo islámico. Barcelona, Edicions Bellaterra, 2009.

Nazih Ayubi. El Islam político. Barcelona. Edicions Bellaterra, 1996.

Wilda Western, Alejandra Galindo e Indira Bernal, Voces, tramas y trayectorias: las protestas populares en Medio oriente y norte de África. México, Universidad Autónoma de Nuevo León - Universidad de Monterrey, 2014.

Recibido: $12 / 09 / 2016$

Evaluado: $31 / 10 / 2016$

Versión Final: 24/11/2016

${ }^{33}$ http://www.milenio.com/internacional/Guerra em Gaza-Jerusalem-Hamas 0 835716423.html 